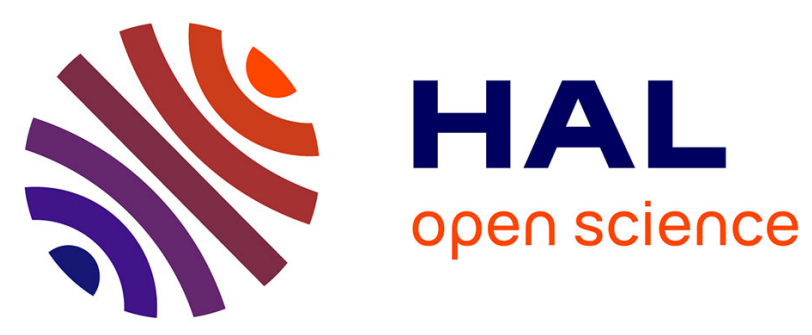

\title{
A model of local kinetics of sorption to understand the water transport in bio-based materials
}

N. Reuge, F. Collet, S. Pretot, S. Moissette, Marjorie Bart, Christophe Lanos

\section{To cite this version:}

N. Reuge, F. Collet, S. Pretot, S. Moissette, Marjorie Bart, et al.. A model of local kinetics of sorption to understand the water transport in bio-based materials. Cuong Ha-Minh; Dong Van Dao; Farid Benboudjema; Sybil Derrible; Dat Vu Khoa Huynh; Anh Minh Tang. CIGOS 2019, Innovation for Sustainable Infrastructure. Proceedings of the 5th International Conference on Geotechnics, Civil Engineering Works and Structures, 54, Springer, pp.495-500, 2020, Lecture Notes in Civil Engineering, 10.1007/978-981-15-0802-8_77. hal-02368114

\section{HAL Id: hal-02368114 \\ https://hal-univ-rennes1.archives-ouvertes.fr/hal-02368114}

Submitted on 30 Mar 2020

HAL is a multi-disciplinary open access archive for the deposit and dissemination of scientific research documents, whether they are published or not. The documents may come from teaching and research institutions in France or abroad, or from public or private research centers.
L'archive ouverte pluridisciplinaire HAL, est destinée au dépôt et à la diffusion de documents scientifiques de niveau recherche, publiés ou non, émanant des établissements d'enseignement et de recherche français ou étrangers, des laboratoires publics ou privés. 


\title{
A model of local kinetics of sorption to understand the water transport in bio-based materials
}

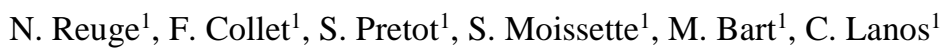

${ }^{1}$ Université Européenne de Bretagne, Laboratoire de Génie Civil et Génie Mécanique, Equipe Matériaux Thermo Rhéologie, IUT Rennes, 3 rue du Clos Courtel, BP 9042235704 Rennes,

France

\begin{abstract}
The classic models describing the hygric mass transfers inside porous materials seem unsuitable in the case of bio-based materials. They are based on the assumption of instantaneous local equilibrium between relative humidity and water content [1]. These two parameters evolve according to the diffusive fluxes following the sorption isotherms. This study shows that it leads to predict much shorter times of stabilization than those experimentally obtained. A new approach is presented here, it frees from the local instantaneous equilibrium introducing a local kinetics to describe the transformation of water from vapor state to liquid state and vice versa. The local kinetics of sorption is coupled with the well-known hysteresis phenomenon. It is adjusted from bibliographic data [2] giving mass evolution of three hemp concretes under adsorption / desorption conditions. 1D cylindrical simulations allows an excellent fitting on the experiments. Finally, a semi-empirical model is proposed, allowing to determine the kinetics parameters more easily. The effect of the local kinetics model on the hygrothermal transfers occurring through a bio-based wall is then studied.
\end{abstract}

Keywords: bio-based porous materials, hemp concrete, local kinetics, sorption, hygric transfer, modeling.

\section{$1 \quad$ Introduction}

Water sorption in porous media involves complex and coupled phenomena such as vapor / liquid water mass transport by Fickian diffusion and equilibrium isotherms of adsorption / desorption associated with hysteretic phenomena [3].

Classic simulation tools of hygrothermal transfers in building materials are based on the assumption that for a given local relative humidity $(\varphi)$, the associated equilibrium local water content $(w)$ is reached instantaneously. Here, various bio-based materials are studied: it is demonstrated that such an assumption leads to serious inconsistencies. Thus, a local kinetics of sorption may exist. It had already been established for bio-based materials $[4,5]$ as well as for traditional cement compounds [6].

The first part of this study is a summary of the hygric characterization performed on three selected hemp concretes [2] and on the bio-based materials developed during the ISOBIO project [7]. Then, the theoretical background necessary to model the 
water sorption is presented. A new expression for the local kinetics of sorption is proposed and validated for the three studied hemp concretes in the following part. Then, a semi-empirical analytical model is proposed, allowing to estimate straightly the kinetic parameters. The final part studies a bio-based multilayered wall developed during the ISOBIO European project: simulations performed with a 1D Cartesian code based on the local kinetics model (TMCKIN) is compared against measurements carried out on a demonstrator (HIVE, Wroughton, UK).

\section{$2 \quad$ Materials characterizations}

\subsection{Classic properties}

The three studied hemp concretes are made of hemp shiv mixed with lime based mineral binders. Their properties had been characterized in [2]. The first one is a precast hemp concrete (PHC) also known as EASY- $\mathrm{R}^{\mathrm{TM}}$, the second one is a sprayed hemp concrete (SHC) and the third one is a molded hemp concrete (MHC).

The ISOBIO materials studied are: a $\mathrm{BCB}^{\mathrm{TM}}$ lime-hemp render $(\mathrm{BCB})$, a $\mathrm{CAVAC}^{\mathrm{TM}}$ Rigid panel made of hemp shiv and an organic binder (CAV), a Biofib Trio flexible from CAVAC ${ }^{\mathrm{TM}}$ made of hemp wool (BIO), an OSB3, a Proclima ${ }^{\mathrm{TM}}$ INTELLO membrane (INT), a Lignicell CSB $^{\mathrm{TM}}$ panel made of straw (CSB) and a CLAYTEC $^{\mathrm{TM}}$ clay-hemp plaster (CLA). Their properties has been studied in [7].

Table 1 is a compilation of the classic properties of all these materials at dry state: the bulk densities $\rho_{0}$, the open porosities $\varepsilon_{0}$, the vapor diffusion resistance factors $\mu_{0}$, the thermal conductivities $\lambda_{0}$ and the specific heat capacities $C p_{0}$.

The Proclima INTELLO membrane is a hygrovariable material evolving very significantly as a function of the relative humidity $R H$ following a logistic power law: $\mu$ $=1000 /\left(7 \cdot 33 \cdot 10^{-3}+1.8 \cdot R H^{7.64}\right)$. The evolution of the thermal conductivities as a function of the water content has been modeled by the self-consistent scheme [8].

Table 1. Materials classic properties

\begin{tabular}{llllll}
\hline Mat. & $\begin{array}{l}\rho_{0} \\
\left(\mathrm{~kg} \cdot \mathrm{m}^{-3}\right)\end{array}$ & $\begin{array}{l}\varepsilon 0 \\
(-)\end{array}$ & $\begin{array}{l}\mu_{0} \\
(-)\end{array}$ & $\begin{array}{l}\lambda_{0} \\
\left(\mathrm{~W} \cdot \mathrm{m}^{-1} \mathrm{~K}^{-1}\right)\end{array}$ & $\begin{array}{l}C p_{0} \\
\left(\mathrm{~J} \cdot \mathrm{kg}^{-1} \cdot \mathrm{K}^{-1}\right)\end{array}$ \\
\hline PHC & 450 & 0.68 & 4 & - & - \\
SHC & 425 & 0.66 & 4 & - & - \\
MHC & 425 & 0.77 & 4 & - & - \\
BCB & 530 & 0.55 & 9 & 0.13 & 1006 \\
CAV & 197 & 0.43 & 9 & 0.07 & 2100 \\
BIO & 28 & 0.35 & 2.5 & 0.039 & 1800 \\
OSB3 & 567 & 0.81 & 130 & 0.13 & 1600 \\
INT & 85 & 0.085 & $1.37 .10^{5}$ & 2.74 & 2500 \\
CSB & 505 & 0.67 & 23 & 0.10 & 1700 \\
CLA & 1392 & 0.29 & 10 & 0.62 & 1040 \\
\hline
\end{tabular}




\subsection{Isotherms of sorption}

The sorption isotherms were measured according to a discontinuous method: the time dependent water content $W$ was determined at successive stages of increasing (and then decreasing) relative humidity at $23^{\circ} \mathrm{C}$ [2]. Note that for the ISOBIO materials, only the adsorption isotherm have been determined [7]. The measured equilibrium water content $W_{e q}$ are fitted here by the Van Genuchten model (VG):

$$
W_{e q}(R H)=W_{\text {sat }}\left[1-(h \ln (R H))^{\eta}\right]^{1-1 / \eta}
$$

where $W_{\text {sat }}$ is the maximum equilibrium local water content (i.e. $1000 \varepsilon_{0}$ ) and $h$ and $\eta$ are adjustment coefficients. The adjustment coefficients are given in Table 2.

Table 2. VG model: adjustment coefficients

\begin{tabular}{lllll}
\hline Mat. & $h_{\text {ads }}(-)$ & $\eta_{\text {ads }}(-)$ & $h_{\text {des }}(-)$ & $\eta_{\text {des }}(-)$ \\
\hline PHC & 166 & 2.05 & 258 & 1.65 \\
SHC & 378 & 1.77 & 500 & 1.46 \\
MHC & 185 & 1.98 & 75 & 1.66 \\
BCB & 8524 & 1.38 & - & - \\
CAV & 4830 & 1.435 & - & - \\
BIO & 198852 & 1.47 & - & - \\
OSB3 & 25410 & 1.325 & - & - \\
INT & 2091 & 1.42 & - & - \\
CSB & 12966 & 1.334 & - & - \\
CLA & 12000 & 1.36 & - & - \\
\hline
\end{tabular}

\section{A model of local kinetics of sorption}

\subsection{Mass transport governing equations}

Assuming that the rate of sorption $R_{s}$ is very fast compared to the vapor diffusive flux (i.e. instantaneous equilibrium $w / \varphi$ assumption), the mass transport can be described by the so-called Künzel single governing equation [1]:

$$
\left.\frac{\partial w}{\partial \varphi}\right|_{T} \frac{\partial \varphi}{\partial t}-\nabla \cdot\left[\left(\frac{\delta_{v}}{\mu} P_{s a t}+\left.D_{p, l} \frac{\partial w}{\partial \varphi}\right|_{T}\right) \nabla \varphi\right]=0
$$

where $\partial w /\left.\partial \varphi\right|_{T}$ is given by the isotherm of sorption.

Now, considering that the instantaneous equilibrium $w / \varphi$ assumption is not justified, there are two mass balance equations to consider:

$$
\left\{\begin{array}{l}
\frac{\partial\left(\varphi P_{s a t}\right)}{\partial t}-\nabla \cdot\left[\frac{\delta_{v}}{\mu} \frac{R T}{M_{w}} \nabla\left(\varphi P_{s a t}\right)\right]=-\frac{R T}{M_{w}} R_{s} \\
\frac{\partial w}{\partial t}-\nabla \cdot\left(D_{p, l} \nabla w\right)=R_{s}
\end{array}\right.
$$


Note that the coupling with a hysteretic model (e.g. [3]) can easily be done: the reversal points are obtained when the sign of $R_{s}$ changes.

\subsection{Sorption rate}

A kinetics is usually expressed as a kinetic constant multiplied by a driving force. The simplest consistent expression that can be conceived for the sorption rate is the following:

$$
R_{s}=k_{0}\left(w_{e q}(\varphi)-w\right)
$$

where $k_{0}$ is the local kinetic constant of sorption (adsorption or desorption) and $w_{e q}$ is the equilibrium local water content given by the sorption isotherm at $\varphi$. [4] came to establish the same expression. However, the value of the kinetic constant $k_{0}$ has to be adjusted to quite different values as a function of the hygric conditions. Consequently, a more complex driving force has been established in our studies introducing a kinetic order of 2 :

$$
R_{s}=k_{0}\left(w_{e q}(\varphi)-w\right)^{2}
$$

\section{$4 \quad$ Validation of the local kinetics model}

The model has been validated comparing the sorption curves measured by [2] performed on $5 \mathrm{~cm}$ diameter cylindrical samples of PHC, SHC and MHC to 1D cylindrical calculations. As evidenced by the results reported in Fig. 1a (adsorption) and 1b (desorption) for PHC, considering a value of $k_{0}$ of 2 day $^{-1} /\left(\mathrm{kg} \cdot \mathrm{m}^{-3}\right)$, the adjustments are globally very good. In adsorption conditions, the stabilizations of the water content occur from 5 days (at low $R H$ ) to several week at high $R H$. If the Künzel equation is considered instead, calculations lead to stabilizations in less than one day!

For SHC and MHC, the adjustments are also very good and lead to $k_{0}$ of 0.65 day $^{-}$ $1 /\left(\mathrm{kg} \cdot \mathrm{m}^{-3}\right)$ and 0.5 day $^{-1} /\left(\mathrm{kg} \cdot \mathrm{m}^{-3}\right)$ respectively.
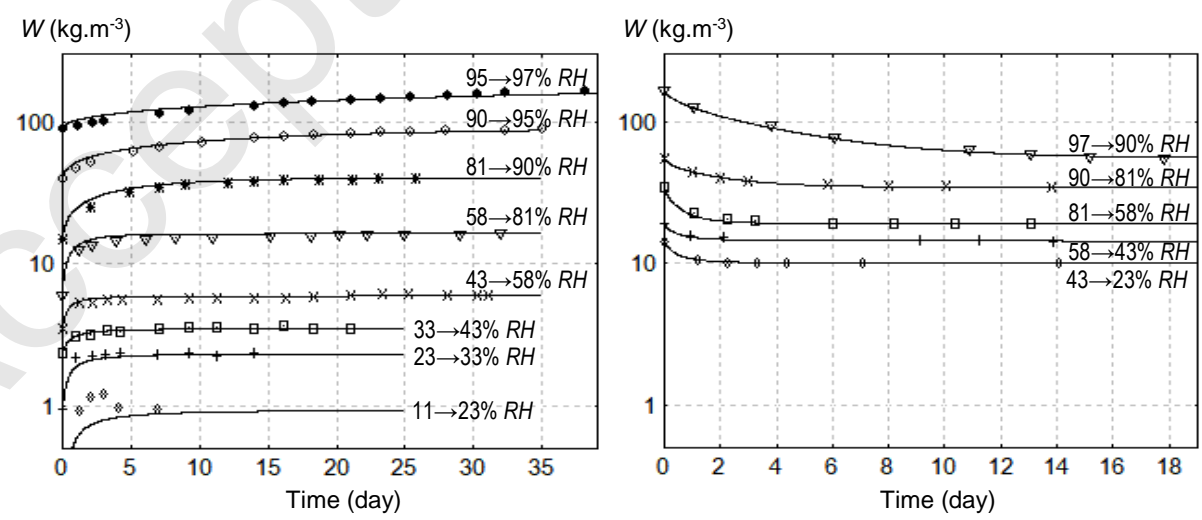

Fig. 1. Temporal evolution of the global water content $W$ in a sample of PHC for (a) increasing / (b) decreasing $R H$ steps - Experiments (points) and simulations (lines), $k_{0}=2$ day $^{-1} /\left(\mathrm{kg} \cdot \mathrm{m}^{-3}\right)$. 


\section{$5 \quad$ A semi-empirical model for kinetic parameters identification}

From [9] focusing on the hydration / dehydration of hydrated minerals, the global kinetics of water adsorption / desorption of a sample can be well described by:

$$
W(t)=\left(W_{i}+W_{f} K_{0} t\right) /\left(1+K_{0} t\right)
$$

where $K_{0}\left(\right.$ day $\left.^{-1}\right)$ is a global kinetic factor. Considering a kinetics order of 2, the following modified expression can be proposed:

$$
W(t)=\left[W_{i}+W_{f}\left(W_{f}-W_{i}\right) K_{0} t\right] /\left[1+\left(W_{f}-W_{i}\right) K_{0} t\right]
$$

where $K_{0}$ is in day $^{-1} /\left(\mathrm{kg} \cdot \mathrm{m}^{-3}\right)$. Now, adjusting this model on the sorption curves, the agreement is good and the following values of $K_{0}$ are obtained: 1.75, 0.6 and 0.45 day $^{-}$ $1 /\left(\mathrm{kg} \cdot \mathrm{m}^{-3}\right)$ for PHC, SHC and MHC respectively. This is quite close to the values of the local kinetic constant $k_{0}$ deduced from the 1D cylindrical calculations.

\section{Simulations of the HIVE demonstrator}

An instrumented ISOBIO reference wall has been set up at the HIVE demonstrator (Wroughton, UK) by the University of Bath (UK). This reference wall consisted in (from outdoor to indoor): $\mathrm{BCB}, 25 \mathrm{~mm}$; CAV, $50 \mathrm{~mm}$; BIO, $145 \mathrm{~mm}$; OSB3, $12 \mathrm{~mm}$; INT, $0.25 \mathrm{~mm}$; BIO, $45 \mathrm{~mm}$; CSB, $40 \mathrm{~mm}$ and CLA, $15 \mathrm{~mm}$. $R H$ and $T$ sensors were set up outdoor and indoor and at various positions inside the wall. The measurements have been performed in winter 2018 during 18 days, i.e. 434 hours

Some samples of these materials have been characterized [7], allowing, thanks to the semi-empirical model (eq. 8), to determine the following kinetic constant $K_{0}$ (day $^{-}$ $1 /\left(\mathrm{kg} . \mathrm{m}^{-3}\right): 0.0014$ for BCB, 0.25 for CAV, 10 for BIO and 0.007 for CSB.

The simulations have been performed with two 1D Cartesian tools: TMC based on the Künzel equation and TMCKIN based on the local kinetics model. Fig. 2 shows the $R H$ measurements and the results of the simulations at the interface BIO / OSB3: Contrary to TMC, TMCKIN predicts the good $R H$ dynamics.

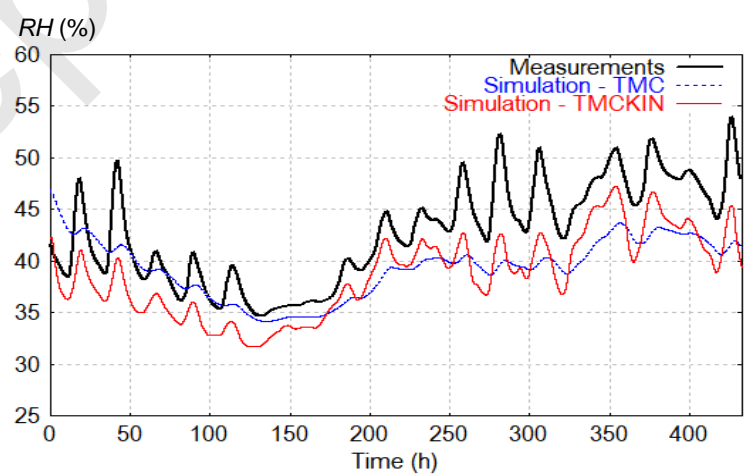

Fig. 2. Temporal evolution of $R H$ at BIO / OSB3 interface - measurements and simulations (TMC and TMCKIN) 


\section{Conclusion}

This study has allowed to understand, model and validate a new phenomenon: the local kinetics of sorption. An expression for the sorption rate has been established and validated.

Beside a homemade code named TMC based on the classic approach, a new 1D simulation tool named TMCKIN has been developed taking into account the local kinetics of sorption. Finally, the data acquired at the HIVE demonstrator inside the ISOBIO multilayered reference wall have been successfully simulated with TMCKIN. TMC underpredicts the dynamics of the $R H$ variations (at the hour / day scale) while TMCKIN leads to results in good agreement with the measurements.

\section{Acknowlegments}

This work has been performed and funded in the framework of the European project ISOBIO - (http://isobioproject.com) within the scope the of the research and innovation program Horizon 2020 (agreement No. 636835). Special thanks goes to Andrew Shea and his team of University of Bath (UK) for having performed the measurements at the HIVE demonstrator.

\section{References}

1. Künzel, H.M.: Simultaneous Heat and Moisture Transport in Building Components - Oneand Two-Dimensional Calculation Using Simple Parameters. Fraunhofer IRB Verlag Suttgart, ISBN 3-8167-4103-7 (1995).

2. Collet, F., Chamoin, J., Pretot, S., Lanos C.: Comparison of the hygric behaviour of three hemp concretes. Energy and Buildings 62, 294-303 (2013).

3. Huang, H.C., Tan, Y.C., Liu, C.W., Chen C.H.: A novel hysteresis model in unsaturated soil. Hydrological Processes 19(8), 1653-1665 (2005).

4. Nyman, U., Gustafsson, P.J., Johannesson, B., Hägglund, R.: Numerical method for the evaluation of non-linear transient moisture flow in cellulosic materials. Int. J. Numer. Meth. Engng 66, 1859-1883 (2006).

5. Frandsen, H.L., Damkilde, L., Svensson, S.: A revised multi-Fickian moisture transport model to describe non-Fickian effects in wood. Holzforschung, Vol. 61, pp. 563-572, Copyright by Walter de Gruyter, Berlin, New York (2007).

6. Zeng, Q., Zhang, D., Li K.: Kinetics and equilibrium isotherms of water vapor adsorption/desorption in cement-based porous materials. Transp. Porous Med. 109, 469-493 (2015).

7. Collet, F., Pretot, S., Colson, V., Gamble, C.R., Reuge, N., Lanos, C.: Hygric properties of materials used for ISOBIO wall solution for new building. Accepted for publication in ICBBM 2019 proceedings, Belfast, UK.

8. Collet, F., Pretot, S.: Thermal conductivity of hemp concretes: Variation with formulation, density and water content. Building Materials 65, 612-619 (2014).

9. Nguyen 2009 Nguyen K.-S.: Comportement thermos-chimique de matériaux minéraux : application à la protection incendie. PhD thesis, LGCGM, Univ Rennes (2009). 